\title{
Shortening of subjective tone intervals followed by repetitive tone stimuli
}

\author{
FUMINORI ONO \\ University of Tokyo, Tokyo, Japan \\ AND \\ SHigeru KitaZaWA \\ Juntendo University School of Medicine, Tokyo, Japan \\ and CREST, Japan Science and Technology Agency, Saitama, Japan
}

\begin{abstract}
Accumulated evidence shows that a subjective time interval is lengthened by preceding or concurrent presentation of flickers or repetitive tone stimuli that have been hypothesized to increase the frequency of pulse generation by a brain pacemaker. In the present study, we presented a series of repetitive tone stimuli after an interval that started and ended with tone markers. We found that subjective perception of the preceding interval was not lengthened but shortened by the tone stimuli that followed the interval. The perceived duration decreased as the frequency of the repetitive tone stimuli increased. The effect disappeared when the repetitive tone stimuli were delivered with a delay of $500 \mathrm{msec}$ after the test interval or when continuous sound was delivered instead of delivering a rapid series of tones. On the basis of the results, we propose that the pulse count accumulated during a test interval was normalized by the clock frequency just after the test interval in a postdictive manner.
\end{abstract}

Accumulated evidence shows that perception of a time interval is lengthened by presenting repetitive tone stimuli (Penton-Voak, Edwards, Percival, \& Wearden, 1996; Treisman, Faulkner, Naish, \& Brogan, 1990) or visual flickers (Droit-Volet \& Wearden, 2002; Treisman et al., 1990; Wearden, 1999) before the test interval. Duration of a rapid series of tones (Burle \& Bonnet, 1997; Burle \& Casini, 2001; Ortega \& López, 2008) or duration of a series of flickering visual stimuli (Kanai, Paffen, Hogendoorn, \& Verstraten, 2006) themselves are perceived as being longer than that of a static stimulus of the same duration. To explain these changes in time perception, researchers generally hypothesize that some kind of internal pacemaker (Creelman, 1962; Treisman, 1963) is accelerated by the repetitive stimulation. Acceleration of the pacemaker leads to an increase in pulse counts during a given period, which eventually leads to a stretch in time perception. It is worth noting that these previous studies examined and explained effects of repetitive stimulation that was presented before or during a test interval to be timed.

The pacemaker framework is embedded in a scalar expectancy theory (SET; Gibbon, Church, \& Meck, 1984), which is one of the most popular contemporary models of time perception. SET proposes that temporal processing consists of three major components: a clock process consisting of a pacemaker and an accumulator, a memory process consisting of short-term and reference-memory stores, and a comparator process in which decisions are made. A number of studies have manipulated the clock component of the model in both animals (Maricq, Roberts, \& Church, 1981; Meck, 1983) and humans (Droit-Volet \& Wearden, 2002; Penton-Voak et al., 1996) and have provided evidence for a pacemaker-accumulator clock of the type that SET proposes. However, much less attention has been devoted to the memory and decision components of the model. One way to examine these components is to deliver an external perturbation during the memory or decision processing and evaluate the effects on time perception.

In a previous study (Ono \& Kitazawa, 2009), we showed that perception of an empty interval (for a review, see Grondin, 2003) demarcated by two visual markers depended critically on the size of the second marker. On the basis of the results, we proposed that signals elicited by a second marker modify the working memory in which the pulse count is stored. This postdictive framework is consistent with previous findings in regard to vision, such as backward masking (Bachmann, 1994), the color-phi phenomenon (Kolers \& von Grünau, 1976), and the flash-lag effect (Eagleman \& Sejnowski, 2000). By analogy to these previous studies, we raised a question of whether and how repetitive stimuli presented after a test interval alter perception of the preceding time interval in a postdictive manner.

If there is no such postdictive mechanism, the repetitive stimulation should have no effect on subjective duration. If there is, repetitive stimulation should accelerate the rate of the internal pacemaker and lead to an increase in time perception. We therefore expected that a time interval followed by the presentation of repetitive stimulation

F. Ono, fuminori@fennel.rcast.u-tokyo.ac.jp 
would remain the same or would be perceived as being longer. We show that, contrary to our expectations, a time interval followed by high-frequency repetitive stimulation was perceived as being shorter than that followed by lowfrequency or no repetitive stimulation.

\section{EXPERIMENT 1}

In Experiment 1, we examined the effects of a rapid series of tones that followed each test interval.

\section{Method}

Participants. Eight paid volunteers participated. New participants were recruited for Experiments 2 through 6. All of the participants had normal hearing and were unaware of the purpose of the experiments. All had given their informed consent prior to participation, in accordance with institutional guidelines.

Apparatus. In a quiet, dark room, seated participants wearing headphones (Sony MDR-Z900HD) responded by using a keyboard.
The sound level was measured with a sound-level meter. Experiments were run on a PC/AT-compatible computer using a ViSaGe stimulus generator (Cambridge Research Systems).

Stimuli. We used high-tone $(1000 \mathrm{~Hz})$ and low-tone $(500 \mathrm{~Hz})$ bursts that lasted for $10 \mathrm{msec}$, including a rise and a fall time of about $1 \mathrm{msec}$ each. A pair of high-tone bursts $(1000 \mathrm{~Hz})$ were presented as markers that delimited the start and the end of each interval. Low-tone bursts $(500 \mathrm{~Hz})$ were used for presenting repetitive stimuli at 5 or $50 \mathrm{~Hz}$. Both tones were presented to both ears at $70 \mathrm{~dB}$ SPL through a pair of headphones.

Procedure. One trial consisted of reference and test intervals (Figure $1 \mathrm{~A}$ ). Each trial was initiated by the participant by pressing a space bar. After $500 \mathrm{msec}$ of silence, a reference interval (400 msec) was presented by delivering the first high-tone burst, followed by the second, with a silent period of $400 \mathrm{msec}$ in between. After 1,500 msec of silence, a test interval was presented. The silent period for each test interval was chosen pseudorandomly from among eight intervals $(100,280,340,380,420,460,520$, or $700 \mathrm{msec})$. After $100 \mathrm{msec}$ of silence, a rapid series of low tones was presented for $1,000 \mathrm{msec}$ at 5 or $25 \mathrm{~Hz}$. The participants judged whether the test interval was longer or shorter than the reference interval and responded by pressing a key

A

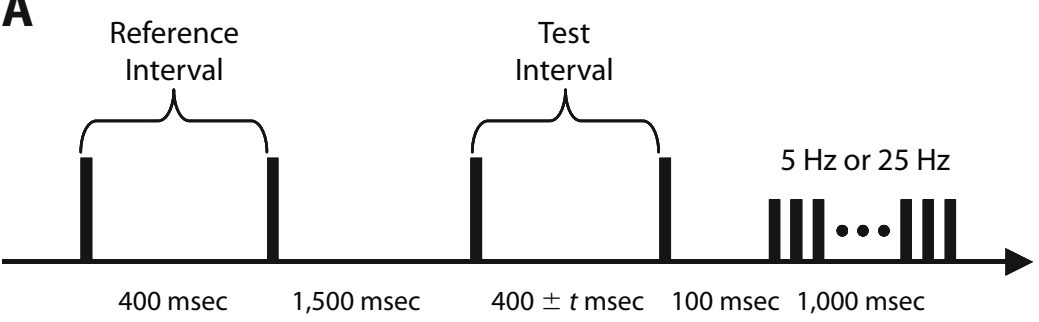

B

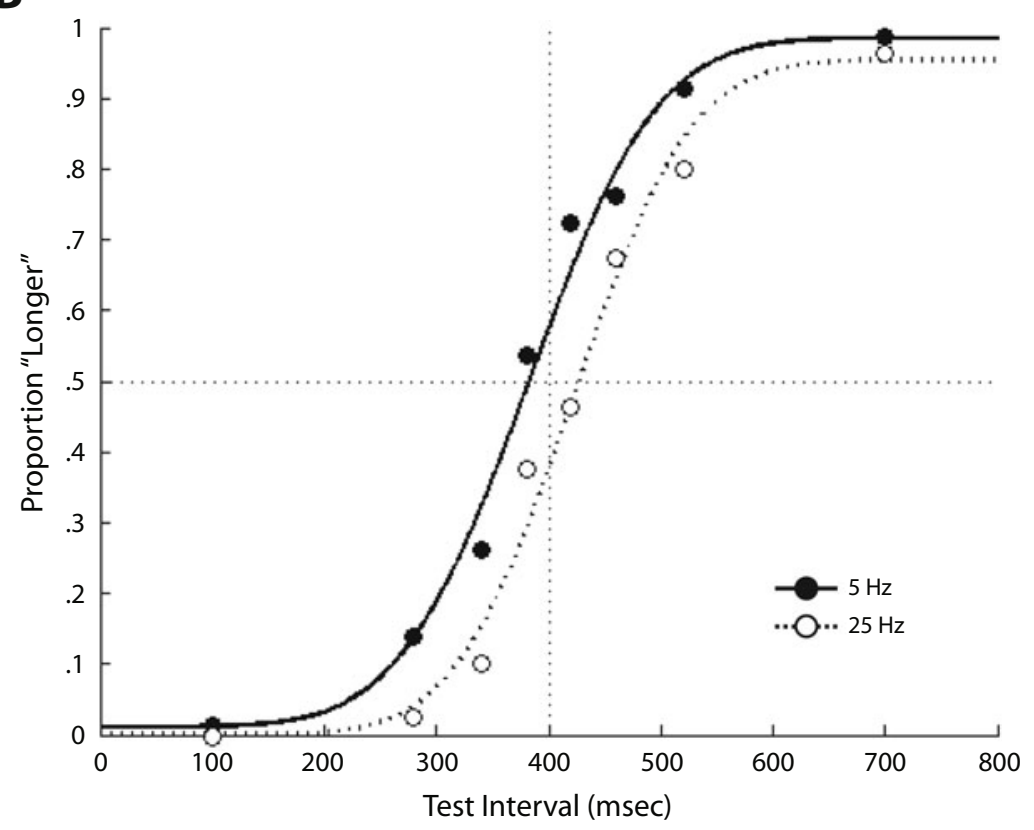

Figure 1. Shortening of subjective tone intervals followed by repetitive tone stimuli (Experiment 1). (A) The sequence of events in one trial is shown along a time line. Taller bars represent high-tone bursts $(1000 \mathrm{~Hz})$. Shorter bars represent low-tone bursts $(500 \mathrm{~Hz})$. Each tone burst lasted for $10 \mathrm{msec}$. After a gap of $100 \mathrm{msec}, 5$ or 25 low-tone bursts followed the test interval in $1,000 \mathrm{msec}$. That is, the frequency of the repetitive stimuli was either 5 or $25 \mathrm{~Hz}$. (B) The probability that the participants judged the test interval as being longer than the reference interval is plotted against the test interval. $A$ vertical broken line at $\mathbf{4 0 0}$ msec shows the length of the reference interval. 
that corresponded to each judgment. No feedback was given in any part of the experiment. Each participant completed 160 trials.

\section{Results and Discussion}

Contrary to our expectation, the proportion of longer judgments was generally smaller at $25 \mathrm{~Hz}$ than at $5 \mathrm{~Hz}$ (Figure 1B). The means of proportion of longer judgments were .54 and .42 at 5 and $25 \mathrm{~Hz}$, respectively. A Kolmogorov-Smirnov test indicated that the distributions of data in all experiments did not differ significantly from a normal distribution $(p>.05)$. Two-way ANOVAs of the proportion of longer judgments with two within-subjects variables revealed that the main effects of repetition rate ( 5 or $25 \mathrm{~Hz}$ ) and test interval (100, 280, 340, 380, 420, 460, 520 , or $700 \mathrm{msec}$ ) and their interaction were significant $[F(1,7)=12.42, p=.009 ; F(7,49)=59.03, p<.001$; and $F(7,49)=2.32, p=.03$, respectively]. Multiple comparisons (Ryan's method) showed that the proportion of longer judgments was significantly lower at $25 \mathrm{~Hz}$ than at $5 \mathrm{~Hz}(p<.05)$ when the test intervals were 340, 380, and $420 \mathrm{msec}$. The point of subjective equality, defined as the intersection of the sigmoid curve with the $\mathrm{P}=.5$ line, was larger in the $25-\mathrm{Hz}$ condition (421 msec) than in the $5-\mathrm{Hz}$ condition $(381 \mathrm{msec})$. When the data were analyzed subject by subject, the mean of the point of subjective equality was significantly larger in the $25-\mathrm{Hz}$ condition than in the $5-\mathrm{Hz}$ condition [paired $t$ test: $t(7)=3.60, p=.009$ ]. These results showed that a test interval was perceived as being shorter when it was followed by a series of tone stimuli repeated at $25 \mathrm{~Hz}$ than when it was followed by a series of tone stimuli repeated at $5 \mathrm{~Hz}$. The next question is whether the subjective time interval becomes shorter as the rate of succeeding repetitive tone stimuli increases.

\section{EXPERIMENT $2^{1}$}

In Experiment 2, we examined whether perceived duration decreases as the frequency of the repetitive tone stimuli increases over a range from $0 \mathrm{~Hz}$ (no tone) to $50 \mathrm{~Hz}$.

\section{Method}

All aspects of this experiment were the same as those in Experiment 1 , except that the rates of succeeding series of tone stimuli were chosen from among four (no tone, 5,25 , or $50 \mathrm{~Hz}$ ) and the test intervals were chosen from among three $(350,400$, or $450 \mathrm{msec})$. Ten paid volunteers participated. Each participant completed 120 trials.

\section{Results and Discussion}

Two-way ANOVAs showed that the main effects of repetition rate (no tone, 5,25 , or $50 \mathrm{~Hz}$ ) and test interval $(350$, 400 , or $450 \mathrm{msec})$ were both significant $[F(3,27)=6.80$, $p=.001$ and $F(2,18)=33.71, p<.001$, respectively], but their interactions were not $[F(6,54)=0.83, p=.52]$ (Figure 2). Paired $t$ tests showed that the subjective duration at $50 \mathrm{~Hz}$ was significantly shorter than at no tone $[t(9)=$ 2.83, $p=.009], 5 \mathrm{~Hz}[t(9)=2.16, p=.01]$, and $25 \mathrm{~Hz}$ $[t(9)=0.93, p=.04]$, and that the subjective duration at $25 \mathrm{~Hz}$ was significantly shorter than that at $5 \mathrm{~Hz}[t(9)=$ $1.23, p=.04]$. These results show that the subjective time interval became shorter as the rate of succeeding repetitive stimulation increased from 0 to $50 \mathrm{~Hz}$.

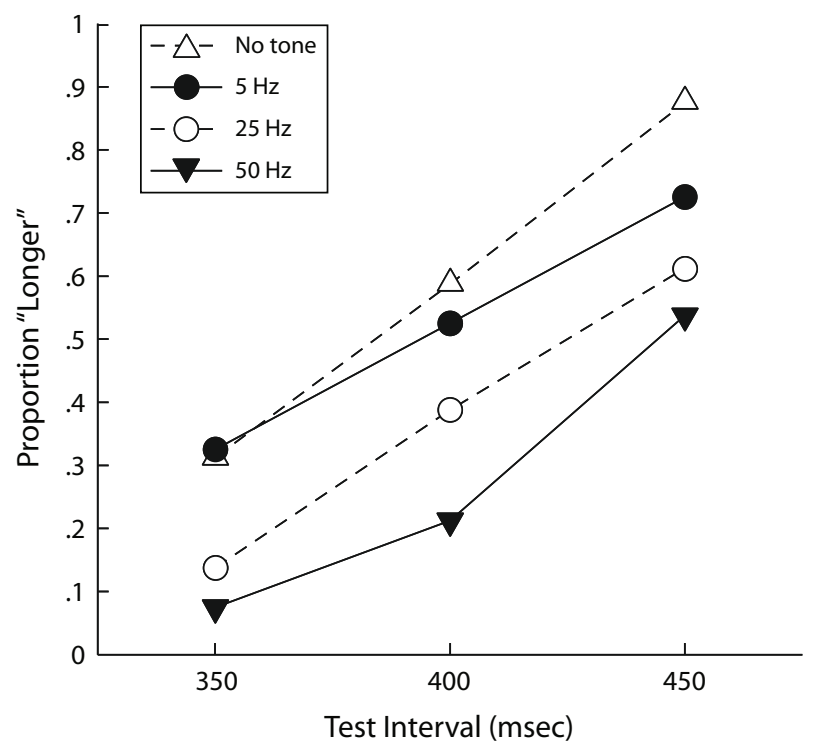

Figure 2. Effects of the frequency of tone stimuli on time perception (Experiment 2). In the no-tone condition, there was a silent period of $1,000 \mathrm{msec}$ after the test interval.

\section{EXPERIMENT 3}

In Experiments 1 and 2, tone stimuli followed each test interval after a fixed gap of $100 \mathrm{msec}$. The next question is how long the repetitive stimuli are effective after the test interval. In Experiment 3, we examined the effect of the gap interval before delivering a rapid series of tones.

\section{Method}

All aspects of this experiment were the same as those in Experiment 1 , except that the rate of rapid tone series was fixed at $25 \mathrm{~Hz}$,

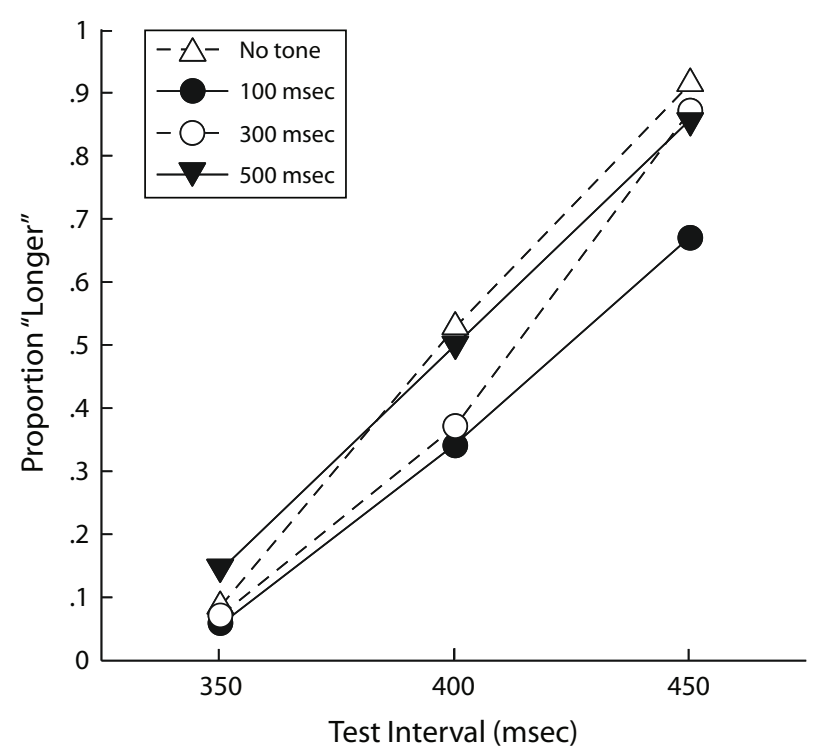

Figure 3. Effects of the gap duration on time perception (Experiment 3). Either the gap duration (see Figure 1A) was chosen from among 100, 300, or $500 \mathrm{msec}$ before delivering a $25-\mathrm{Hz}$ series of tone bursts or no tone bursts were delivered. 
the gap interval was chosen from among four $[100,300,500 \mathrm{msec}$, or infinity (no tone)], and the test intervals were chosen from among three $(350,400$, or $450 \mathrm{msec})$. Seven paid volunteers participated. Each participant completed 120 trials.

\section{Results and Discussion}

The main effects of both gap interval $(100,300,500 \mathrm{msec}$, or no tone) and test interval $(350,400$, or $450 \mathrm{msec})$ were significant $[F(3,18)=3.70, p=.03$, and $F(2,12)=$ $111.21, p<.001$, respectively], but their interaction was not $[F(6,36)=2.01, p=.08]$ (Figure 3). Paired $t$ tests showed that the subjective duration was significantly shorter when the gap intervals were $100 \mathrm{msec}[t(6)=$ $1.52, p=.007]$ and $300 \mathrm{msec}[t(6)=0.71, p=.02]$ than when there was no tone. When the gap interval was $500 \mathrm{msec}$, the judgment was not significantly different from that in the no-tone condition $[t(6)=0.09, p=.87]$. The results show that the shortening effect due to succeeding repetitive stimuli fades away within $500 \mathrm{msec}$ after the test interval.

\section{EXPERIMENT 4}

In Experiments 1, 2, and 3, the repetitive tone stimuli were presented after the target interval. In Experiment 4, we examined the effect of repetitive stimuli delivered before the onset of the test interval. On the basis of previous studies (Penton-Voak et al., 1996; Treisman et al., 1990), we expected a time interval preceded by high-frequency repetitive stimulation to be perceived as being longer than that preceded by low-frequency repetitive stimulation.

\section{Method}

All aspects of this experiment were the same as those in the first experiment, except that the series of tones was presented before the test interval (Figure 4A). Eight paid volunteers participated. Each participant completed 160 trials.

\section{Results and Discussion}

Two-way ANOVAs revealed that the main effects of repetition rate $(5$ or $25 \mathrm{~Hz}$ ) and test interval and their interac-
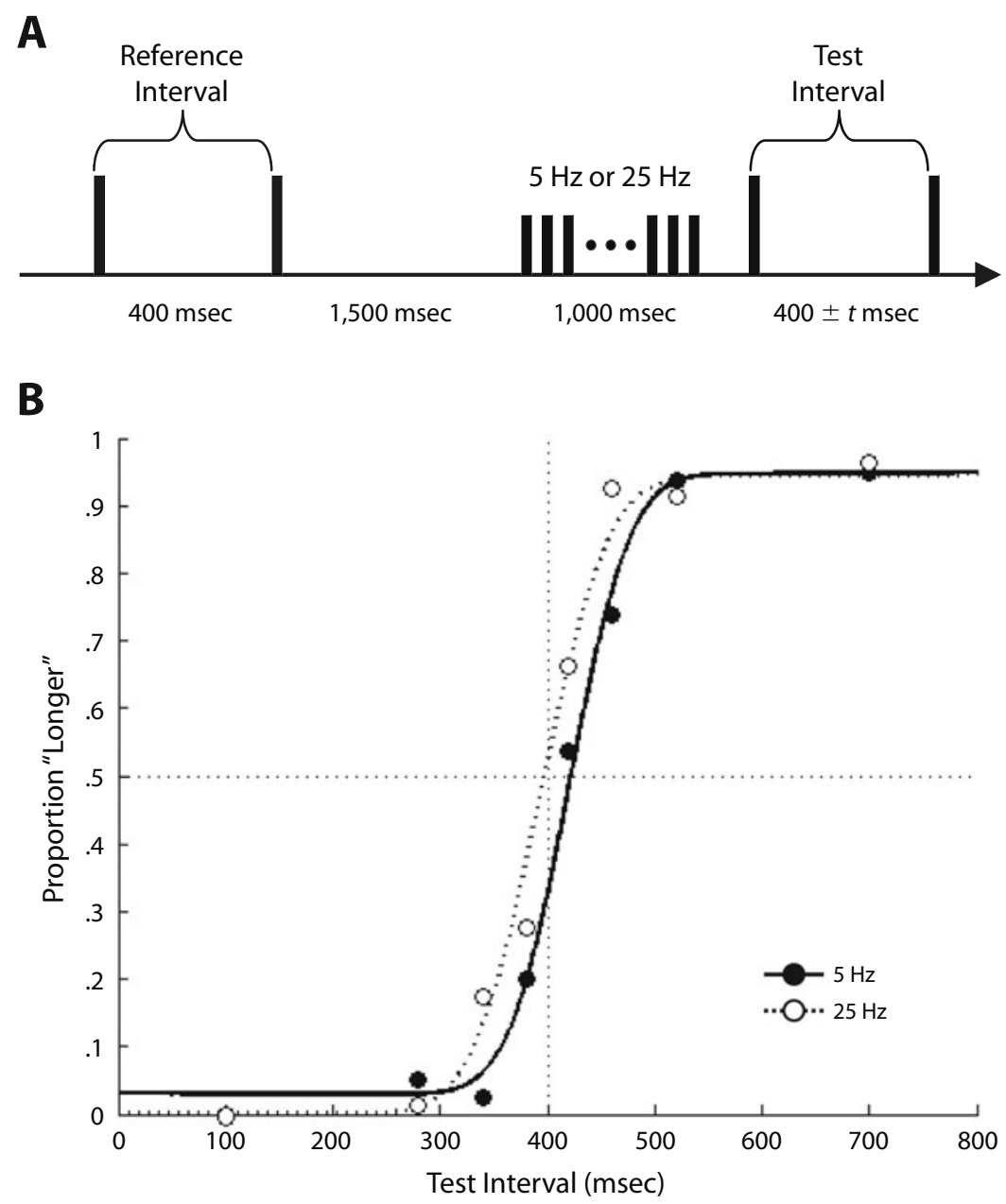

Figure 4. Lengthening of subjective tone intervals preceded by repetitive tone stimuli (Experiment 4). (A) A rapid series of tones $(5$ or $25 \mathrm{~Hz}$ ) was delivered for $1,000 \mathrm{msec}$ before the test interval. (B) The probability that the participants judged the test interval as being longer than the reference interval is plotted against the test interval. $A$ vertical broken line at $\mathbf{4 0 0} \mathbf{m s e c}$ shows the length of the reference interval. 
tion were significant $[F(1,7)=8.12, p=.02 ; F(7,49)=$ $253.44, p<.001$; and $F(7,49)=2.76, p=.01$, respectively] (Figure 4B). Multiple comparisons showed that the subjective time interval was significantly longer in the $25-\mathrm{Hz}$ condition than that in the $5-\mathrm{Hz}$ condition $(p<.05)$ when the test intervals were 340,420 , and $460 \mathrm{msec}$. The point of subjective equality was smaller in the $25-\mathrm{Hz}$ condition $(393 \mathrm{msec})$ than in the $5-\mathrm{Hz}$ condition $(420 \mathrm{msec})$. When the data were analyzed subject by subject, the mean of the point of subjective equality was significantly smaller in the $25-\mathrm{Hz}$ condition than in the $5-\mathrm{Hz}$ condition [paired $t$ test: $t(7)=3.09, p=.01]$. It is worth noting that the effects of the same-tone stimuli were reversed, depending on whether the stimuli were presented before (Experiment 4) or after (Experiments 1, 2, and 3) the test interval. Stimuli presented before the test interval lengthened, but those presented after the test interval shortened subjective duration.

\section{EXPERIMENT 5A}

The results thus far strongly suggest that a rapid series of tones presented after a test interval shortens subjective duration of the test interval and that the effect is correlated with the frequency of the tone bursts. However, it could still be argued that it was not the frequency but the subjective duration of the series of tones that correlated with the postdictive shortening effect, because the $25-\mathrm{Hz}$ series lasting for $1,000 \mathrm{msec}$ should be perceived as being longer than the 5-Hz series of the same physical duration. To test this possibility, we adjusted the subjective duration of the $25-\mathrm{Hz}$ series of tones with that of the $5-\mathrm{Hz}$ series.

\section{Method}

The repetitive tone of $5 \mathrm{~Hz}$ was presented for $1,000 \mathrm{msec}$ (reference duration), and, after $1,500 \mathrm{msec}$ of silence, the repetitive tone of $25 \mathrm{~Hz}$ was presented for a duration chosen pseudorandomly from among eight durations $(480,720,880,960,1,040,1,120,1,280$, or $1,520 \mathrm{msec}$ ) (Figure 5A). The participants judged whether the test duration was longer than the reference duration. Six paid volunteers participated. Each participant completed 80 trials. The apparatus and stimuli of this experiment were the same as those in Experiment 1.

\section{Results and Discussion}

In agreement with the previous studies (Burle \& Bonnet, 1997; Burle \& Casini, 2001; Ortega \& López, 2008), the psychometric function in Figure 5B shows that the $25-\mathrm{Hz}$ series lasting for $1,000 \mathrm{msec}$ was generally perceived as being longer than the $5-\mathrm{Hz}$ series of the same duration. The intercept of the psychometric function with $\mathrm{P}=.5$ shows that the $25-\mathrm{Hz}$ series lasting for $937 \mathrm{msec}$ was equivalent in subjective duration to the $5-\mathrm{Hz}$ series lasting for $1,000 \mathrm{msec}$.

\section{EXPERIMENT 5B}

In Experiment 5B, we compared the effects of stimulation frequency after adjusting the subjective duration of

C

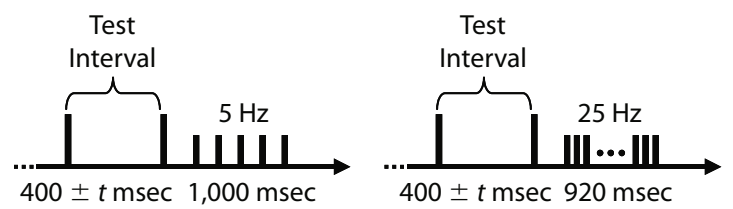

D

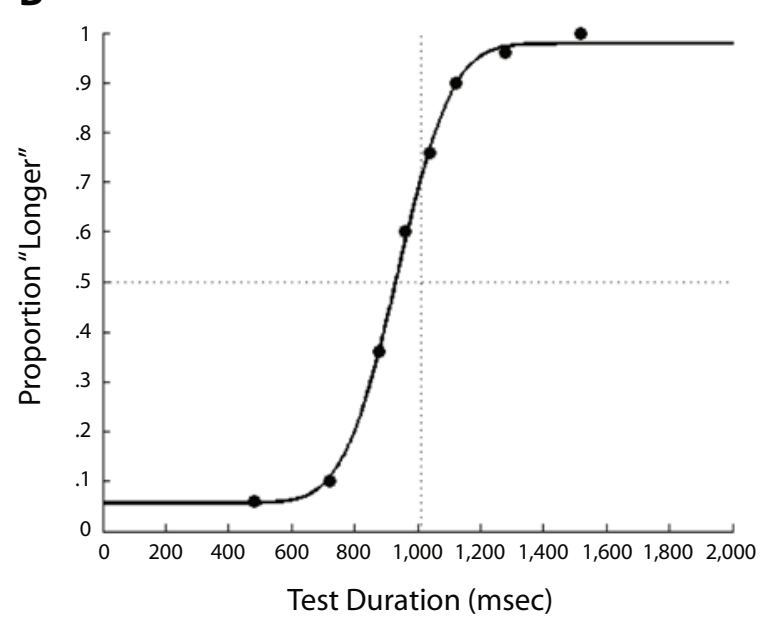

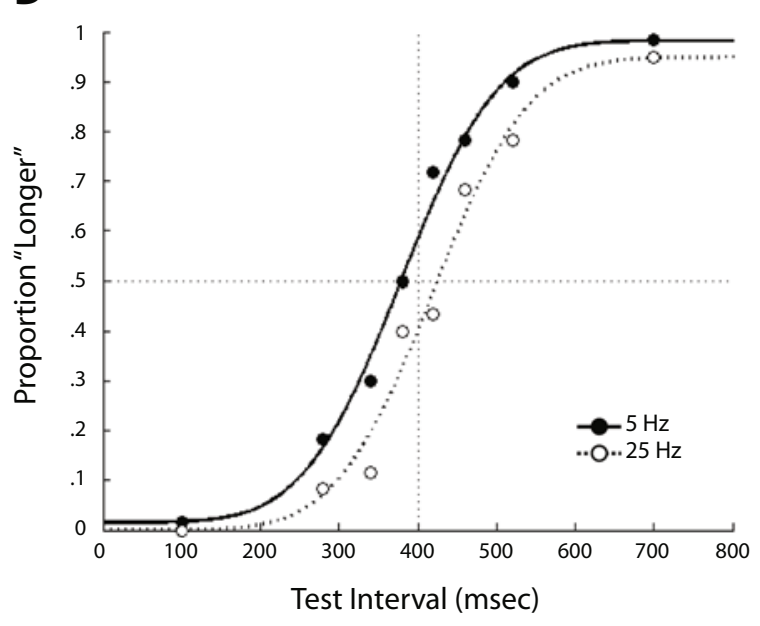

Figure 5. Effects of the frequency of repetitive tone bursts after adjustment of subjective durations of the tone bursts (Experiments 5A and 5B). (A) The subjective duration of the repetitive tone bursts at $5 \mathrm{~Hz}(1,000 \mathrm{msec})$ was compared with the subjective duration of those at $25 \mathrm{~Hz}$. (B) The probability that the participants judged the test duration as being longer than the reference duration is plotted against the test duration. A vertical broken line at $1,000 \mathrm{msec}$ shows the length of the reference duration. (C) The sequence of events in one trial is shown along a time line. (D) The probability that the participants judged the test interval as being longer than the reference interval is plotted against the test interval. 
the $5-\mathrm{Hz}$ and $25-\mathrm{Hz}$ tone series. In this experiment, the test interval was followed by a series of repetitive tone bursts of $5 \mathrm{~Hz}$ lasting for $1,000 \mathrm{msec}$, and the test interval was followed by repetitive tone bursts of $25 \mathrm{~Hz}$ lasting for $920 \mathrm{msec}$. Note that the subjective durations of the repetitive tone bursts were almost equivalent.

\section{Method}

All aspects of this experiment were the same as those in Experiment 1, except that the duration of a $25-\mathrm{Hz}$ series of tones was $920 \mathrm{msec}$, whereas that of a $5-\mathrm{Hz}$ series was $1,000 \mathrm{msec}$ (Figure 5C). Six paid volunteers participated. Each participant completed 160 trials.

\section{Results and Discussion}

Two-way ANOVAs revealed that the main effects of repetition rate $(5 \mathrm{~Hz}$ or $25 \mathrm{~Hz})$ and test interval were significant $[F(1,5)=11.70, p=.01$ and $F(7,35)=$ $60.46, p<.001$, respectively], but their interaction was not $[F(7,35)=1.67, p=.14]$ (Figure 5D). The point of subjective equality was smaller in the $25-\mathrm{Hz}$ condition $(418 \mathrm{msec})$ than in the $5-\mathrm{Hz}$ condition $(378 \mathrm{msec})$. When the data were analyzed subject by subject, the mean of the point of subjective equality was significantly larger in the $25-\mathrm{Hz}$ condition than in the $5-\mathrm{Hz}$ condition [paired $t$ test: $t(5)=2.68, p=.04]$. The results generally agreed with those of Experiment 1 and eliminated the possibility that the effect depended on the subjective duration of the succeeding rapid series of tones.

\section{EXPERIMENT 6}

It could still be argued that it is not the frequency but the total amount of sound energy that was responsible for the shortening effect. In the $5-\mathrm{Hz}$ condition in the first experiment, we used five $500-\mathrm{Hz}$ tone bursts, each lasting $10 \mathrm{msec}$. In the $25-\mathrm{Hz}$ condition, we used 25 tone bursts, so the energy was 5 times as large in the $25-\mathrm{Hz}$ condition as that in the 5-Hz condition. In Experiment 6, we examined whether the sound energy was responsible. For this purpose, instead of delivering a rapid series of tones, we presented continuous sound $(500 \mathrm{~Hz})$ for 50 or $250 \mathrm{msec}$ after the test interval.

\section{Method}

All aspects of this experiment were the same as those in Experiment 1 , except that continuous sound $(500 \mathrm{~Hz})$ was delivered for 50 or $250 \mathrm{msec}$ after the test interval (Figure 6A). Nine paid volunteers participated. Each participant completed 160 trials.

\section{Results and Discussion}

As is shown in Figure 6B, there was little effect of sound energy or sound duration. Two-way ANOVAs revealed that the main effect of test interval was significant $[F(7,56)=$ $103.81, p<.001]$, but neither the main effect of sound duration $(50$ or $250 \mathrm{msec}$ ) nor the sound energy $\times$ sound duration interaction was significant $[F(1,8)=0.57, p=.46$ and $F(7,56)=1.70, p=.12$, respectively]. The point of subjective equality in the 50 -msec condition $(393 \mathrm{msec})$ was almost the same as that in the 250 -msec condition ( $381 \mathrm{msec}$ ). When the data were analyzed subject by subject, the mean of the point of subjective equality in the 50-msec condition was not significantly different from that in the 250 -msec condition [paired $t$ test: $t(8)=1.12, p=.29$ ]. The results rule out the possibility that the postdictive shortening effects depended on the amount of sound energy delivered and suggest that the effect occurs with a series of repetitive tone bursts, but not with a continuous sound. The mean of the proportion of correct responses in the $250-\mathrm{msec}$ condition $(64 \%)$ was significantly lower than that in the 50 -msec condition (68\%) [paired $t$ test: $t(8)=2.35, p=.04$ ]. The results suggest that temporal judgment gets more difficult with the increased length of continuous sound.

\section{GENERAL DISCUSSION}

The present results clearly indicate that a series of repetitive tone stimuli presented after a test interval shortens the subjective duration of the test interval and that this subjective shortening is more noticeable when the repetition frequency is higher. In contrast, the subjective duration of a test interval is lengthened when a rapid series of sounds is presented before the test interval; this was shown in the present study, as well as in some previous studies (Droit-Volet \& Wearden, 2002; Penton-Voak et al., 1996; Treisman et al., 1990; Wearden, 1999). It is worth noting that the effects of tone stimuli were reversed, depending on whether the stimuli were delivered before or after the test interval. Our findings are novel in two respects. First, they are the first to show that postdiction has any influence on the perception of time. Second, the effect was in the direction of shortening the subjective duration.

As was noted in the introduction, the internal pacemaker account (Creelman, 1962; Treisman, 1963) predicts that subjective time intervals should become longer as the rate of repetitive presentation becomes higher. In a clear departure from this prediction, our study shows that subjective time intervals became shorter as the frequency of repetitive stimuli increased. Thus, our results cannot be explained by the internal pacemaker account per se, but they do suggest that there are contributions from some other processes, such as the memory or decision components in temporal processing. This agrees with recent theories that hypothesize that a working memory forms the basis of temporal perception (Lewis \& Miall, 2006; Matell \& Meck, 2004; Niki \& Watanabe, 1979; Staddon, 1974; Staddon \& Higa, 1999).

Other studies (Miyauchi \& Nakajima, 2005; Nakajima et al., 2004; Nakajima, ten Hoopen, \& van der Wilk, 1991; ten Hoopen, Miyauchi, \& Nakajima, 2008) have reported that a time interval that is immediately preceded or followed by another, shorter time interval is perceived as being shorter (the temporal assimilation effect). Because the onset-onset interval between two neighboring tone bursts in the present study was $40 \mathrm{msec}$ at $25 \mathrm{~Hz}$, the test interval (100 to $700 \mathrm{msec}$ ) might be perceived as being shorter due to the temporal assimilation effect. However, temporal assimilation of two neighboring intervals is reported to occur only when the intervals are smaller than $250 \mathrm{msec}$ and when their difference is below $100 \mathrm{msec}$. In our study, the shortening effect was significant when the 

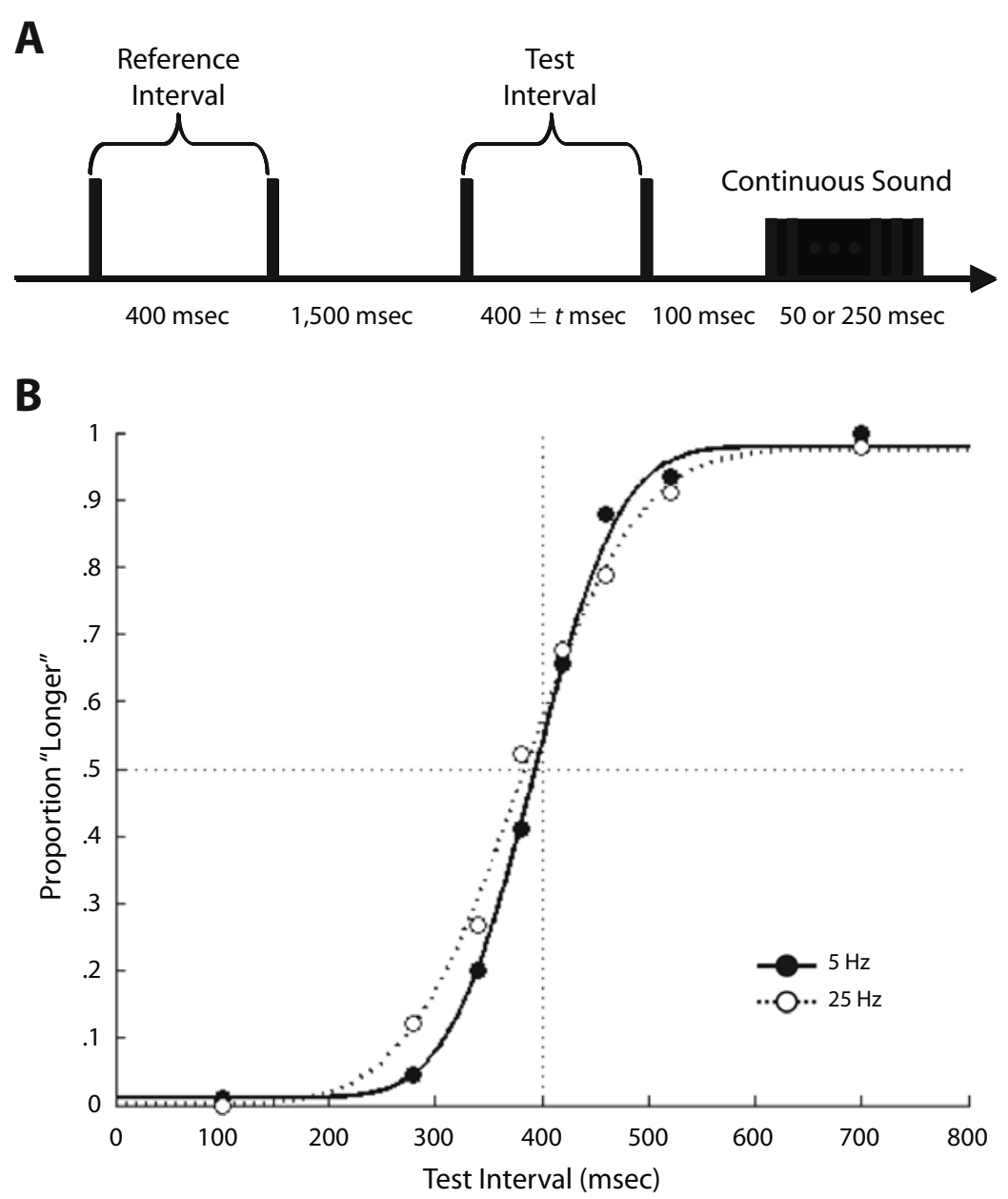

Figure 6. Effects of the duration of continuous sound stimuli after the test interval (Experiment 6). (A) A continuous sound $(500 \mathrm{~Hz}$ ) was presented for 50 or $250 \mathrm{msec}$ after the test interval. (B) The probability that the participants judged the test interval as being longer than the reference interval is plotted against the test interval.

test interval was around $400 \mathrm{msec}$ and the interval difference was larger than $300 \mathrm{msec}$. These values are clearly out of range of those in the reported temporal assimilation. In addition, temporal assimilation cannot explain the lengthening of the test interval when it was preceded by the rapid series of tones. Thus, none of the present findings can be explained by the temporal assimilation effect.

Recent studies (Burr, Tozzi, \& Morrone, 2007; Johnston, Arnold, \& Nishida, 2006) have demonstrated that adaptation to high-frequency visual stimuli decreased subjective duration of another visual stimulus at the location where the high-frequency stimulus had been presented. This phenomenon may seem analogous to the present findings. However, the present findings are completely different in that the reduction of subjective duration occurred when the high-frequency stimuli were presented not before but after the test interval. This precludes any possibility of explaining the present results in terms of adaptation to the high-frequency stimulus.

The foregoing begs the question of how these modifications can depend on the rate of the following repetitive stimulation. It is possible that repetitive stimulation elongated the reference interval of the next trial. However, the present results have nothing to do with this possibility, because the judgments were sorted by the type of stimuli presented after the test stimuli, not by the type of stimuli presented before the test stimuli.

To explain our results, we propose a retrospective evaluation mechanism that depends on the current rate of the internal pacemaker. It is generally accepted that pulses from an internal clock are accumulated during a time interval to be estimated (Creelman, 1962; Treisman, 1963). We propose that, in addition, the pulse count in a working memory is further normalized by the current frequency of the internal pacemaker. Suppose, for example, that a person with a pacemaker of 10 pulses/sec timed a $1-\mathrm{sec}$ interval that was immediately followed by a rapid series of tones. Ten pulses would be stored in his working memory at the end of the 1-sec interval, but the succeeding series of tones would speed up the internal pacemaker to 11 pulses/sec. We propose that the stored pulse count (10 pulses) would be normalized by the clock speed (11 pulses/sec) imme- 


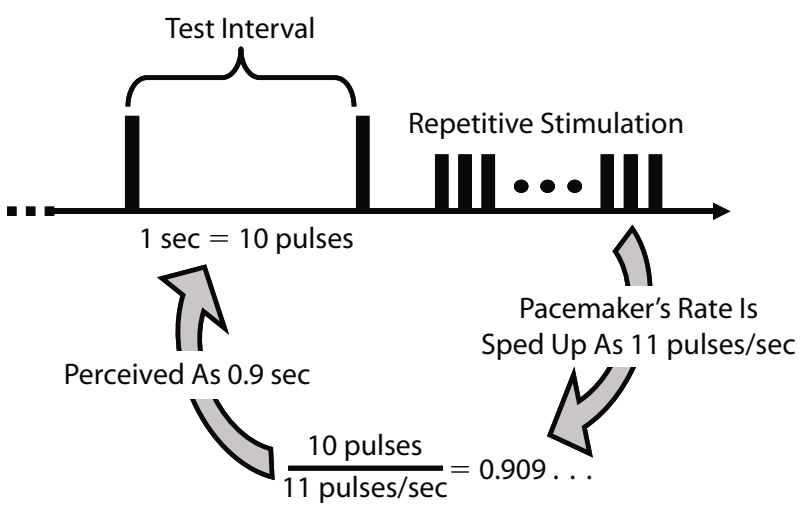

Figure 7. A model of retrospective normalization of subjective duration by the frequency (e.g., 10 pulses/sec) of an internal pacemaker.

diately after the end of the pulse counting in a postdictive manner. Then the perceived duration would be shortened by about $10 \%$ (Figure 7 ) as compared with when the clock speed remains constant $(10$ pulses $/ \mathrm{sec})$. On the basis of the results of the third experiment, we suggest that the hypothesized normalization depends on the clock speed within 500 msec after the end of the timed interval.

By using our hypothesis, we might be able to explain the perisaccadic underestimation of interflash intervals shown in Morrone, Ross, and Burr (2005). Observers in that study consistently underestimated an interval between two flashes when the pair of flashes was immediately followed by a saccade. The interval underestimation has been explained by deceleration of an internal pacemaker (Morrone et al., 2005), a change in spatiotemporal tuning of neurons (Burr \& Morrone, 2006; Ibbotson, Crowder, \& Price, 2006), or the reduction of stimulus visibility (Terao, Watanabe, Yagi, $\&$ Nishida, 2008) around the time of the saccades. These accounts, however, still await further empirical validation. An alternative (although not exclusive) possibility is that the interval underestimation before a saccade might be due to acceleration of the internal pacemaker after the saccade. That is, if the internal pacemaker is sped up right after a saccade, pulses accumulated before the saccade might be underestimated due to the postdictive normalization process. This explanation does not seem implausible, since subjective duration does increase after the saccade (Yarrow, Haggard, Heal, Brown, \& Rothwell, 2001).

The normalization process should be useful for canceling long-term fluctuations in the clock speed and for maintaining homeostasis in time perception. Although it is not clear how the pulse count is normalized retrospectively, at least, presently accepted models of time perception cannot explain the present findings. We believe our hypothesis warrants further testing.

\section{AUTHOR NOTE}

This study was supported in part by Grants-in-Aid for Scientific Research (A) No. 18200024 to S.K. and by a grant from the Research Fellowships of the Japan Society for the Promotion of Science for Young Scientists to F.O. Correspondence concerning this article should be addressed to F. Ono, Research Center for Advanced Science and Technol- ogy, University of Tokyo, 4-6-1, Komaba, Meguro-ku, Tokyo 153-8904, Japan (e-mail: fuminori@fennel.rcast.u-tokyo.ac.jp).

\section{REFERENCES}

Bachmann, T. (1994). Psychophysiology of visual masking: The fine structure of conscious experience. Commack, NY: Nova Science.

Burle, B., \& Bonnet, M. (1997). Further argument for the existence of a pacemaker in the human information processing system. Acta Psychologica, 97, 129-143.

Burle, B., \& CASINI, L. (2001). Dissociation between activation and attention effects in time estimation: Implications for internal clock models. Journal of Experimental Psychology: Human Perception \& Performance, 27, 195-205.

Burr, D., \& Morrone, [M.] C. (2006). Perception: Transient disruptions to neural space-time. Current Biology, 16, R847-R849.

Burr, D., Tozzi, A., \& Morrone, M. C. (2007). Neural mechanisms for timing visual events are spatially selective in real-world coordinates. Nature Neuroscience, 10, 423-425.

Creelman, C. D. (1962). Human discrimination of auditory duration. Journal of the Acoustical Society of America, 34, 582-593.

Droit-Volet, S., \& Wearden, J. (2002). Speeding up an internal clock in children? Effects of visual flicker on subjective duration. Quarterly Journal of Experimental Psychology, 55B, 193-211.

Eagleman, D. M., \& SeJnowski, T. J. (2000). Motion integration and postdiction in visual awareness. Science, 287, 2036-2038.

Gibbon, J., Church, R. M., \& Meck, W. (1984). Scalar timing in memory. In J. Gibbon \& L. Allan (Eds.), Timing and time perception (Annals of the New York Academy of Sciences, Vol. 423, pp. 52-77). New York: New York Academy of Sciences.

Grondin, S. (2003). Processing time between visual events. Brazilian Archives of Ophthalmology, 66, 96-104.

Ibbotson, M. R., Crowder, N. A., \& Price, N. S. C. (2006). Neural basis of time changes during saccades. Current Biology, 16, R834-R836.

Johnston, A., ARnOLD, D. H., \& NishidA, S. (2006). Spatially localized distortions of event time. Current Biology, 16, 472-479.

Kanai, R., Paffen, C. L. E., Hogendoorn, H., \& Verstraten, F. A. J. (2006). Time dilation in dynamic visual display. Journal of Vision, $\mathbf{6}$, $1421-1430$

Kolers, P. A., \& VON GrünaU, M. (1976). Shape and color in apparent motion. Vision Research, 16, 329-335.

Lewis, P. A., \& Miall, R. C. (2006). Remembering the time: A continuous clock. Trends in Cognitive Sciences, 10, 401-406.

MaricQ, A. V., Roberts, S., \& Church, R. M. (1981). Methamphetamine and time estimation. Journal of Experimental Psychology: Animal Behavior Processes, 7, 18-30.

Matell, M. S., \& Meck, W. H. (2004). Cortico-striatal circuits and interval timing: Coincidence detection of oscillatory processes. Cognitive Brain Research, 21, 139-170.

MEcK, W. H. (1983). Selective adjustment of the speed of internal clock and memory processes. Journal of Experimental Psychology: Animal Behavior Processes, 9, 171-201.

MiYauchi, R., \& NAKAJIMA, Y. (2005). Bilateral assimilation of two neighboring empty time intervals. Music Perception, 22, 411-424.

Morrone, M. C., Ross, J., \& Burr, D. (2005). Saccadic eye movements cause compression of time as well as space. Nature Neuroscience, $\mathbf{8}$, 950-954.

Nakajima, Y., ten Hoopen, G., Sasaki, T., Yamamoto, K., Kadota, M., Simons, M., \& Suetomi, D. (2004). Time-shrinking: The process of unilateral temporal assimilation. Perception, 33, 1061-1079.

Nakajima, Y., ten Hoopen, G., \& van Der Wilk, R. (1991). A new illusion of timing perception. Music Perception, 8, 431-448.

Niki, H., \& Watanabe, M. (1979). Prefrontal and cingulate unit activity during time behavior in the monkey. Brain Research, 171, 213-224.

Ono, F., \& Kitazawa, S. (2009). The effect of marker size on the perception of an empty interval. Psychonomic Bulletin \& Review, 16, 182-189.

OrTeGa, L., \& LóPez, F. (2008). Effects of visual flicker on subjective time in a temporal bisection task. Behavioural Processes, 78, 380-386.

Penton-Voak, I. S., Edwards, H., Percival, A., \& Wearden, J. H. (1996). Speeding up an internal clock in humans? Effects of click trains on subjective duration. Journal of Experimental Psychology: Animal Behavior Processes, 22, 307-320. 
Staddon, J. E. R. (1974). Temporal control, attention, and memory. Psychological Review, 81, 375-391.

Staddon, J. E. R., \& Higa, J. J. (1999). Time and memory: Towards a pacemaker-free theory of interval timing. Journal of the Experimental Analysis of Behavior, 71, 215-251.

ten Hoopen, G., Miyauchi, R., \& NaKajima, Y. (2008). Time-based illusions in the auditory mode. In S. Grondin (Ed.), Psychology of time (pp. 139-188). Bingley, U.K.: Emerald Group.

Terao, M., Watanabe, J., Yagi, A., \& Nishida, S. (2008). Reduction of stimulus visibility compresses apparent time intervals. Nature Neuroscience, 11, 541-542.

Treisman, M. (1963). Temporal discrimination and the indifference interval: Implications for a model of the "internal clock." Psychological Monographs, 77(13, Whole No. 576).

Treisman, M., Faulkner, A., Naish, P. L., \& Brogan, D. (1990). The internal clock: Evidence for a temporal oscillator underlying time perception with some estimates of its characteristic frequency. Perception, 19, 705-743.

WeArden, J. H. (1999). "Beyond the fields we know ... ": Exploring and developing scalar timing theory. Behavioural Processes, 45, 3-21.
Yarrow, K., Haggard, P., Heal, R., Brown, P., \& Rothwell, J. C. (2001). Illusory perceptions of space and time preserve cross-saccadic perceptual continuity. Nature, 414, 302-305.

\section{NOTE}

1. We conducted a pilot experiment to compare effects of lower frequency of repetitive stimulation. Seven students participated in the experiment with the same procedure as that used in Experiment 2, except that the frequencies of repetitive stimuli were 4,8 , and $12.5 \mathrm{~Hz}$. The means of proportion of longer judgments were .57, .44, and .29 at 4-, 8-, and $12.5-\mathrm{Hz}$ conditions, respectively. Paired $t$ tests showed that the subjective duration at $12.5 \mathrm{~Hz}$ was significantly shorter than those at $4 \mathrm{~Hz}$ $[t(6)=3.24, p=.01]$ and $8 \mathrm{~Hz}[t(6)=2.58, p=.04]$. This pattern of results was consistent with the findings in the present study.

(Manuscript received July 17, 2009;

revision accepted for publication September 28, 2009.) 